Research Article

\title{
New Purinyl-Steroid and Other Constituents from the Marine Fungus Penicillium brefeldianum ABC190807: Larvicidal Activities against Aedes aegypti
}

\author{
Zong-Min Hou (D, Sen-Quan Yu, Min Tao, Cai-Bei Xia, Yu-Lian Xia, Xian-Feng Wu, \\ and Cun-Zhu Dong $\mathbb{D}$
}

Key Laboratory of Green Prevention and Control of Tropical Plant Diseases and Pests, Ministry of Education, College of Plant Protection, Hainan University, Haikou 570228, China

Correspondence should be addressed to Cun-Zhu Dong; czd@hainanu.edu.cn

Received 16 October 2020; Revised 17 January 2021; Accepted 6 February 2021; Published 18 February 2021

Academic Editor: Xinyong Liu

Copyright ( 2021 Zong-Min Hou et al. This is an open access article distributed under the Creative Commons Attribution License, which permits unrestricted use, distribution, and reproduction in any medium, provided the original work is properly cited.

\begin{abstract}
Mosquitoes historically threatened human health; the major mosquito-related global health issues include malaria, dengue fever, yellow fever, and Zika, as well as several other vector-borne outbreaks. Here, the EtOAc extract of the mangrove sediment fungus Penicillium brefeldianum ABC190807 exerted larvicidal activities against the third instar larvae of Aedes aegypti with an LC s0 $_{0}$ $0.089 \mathrm{mg} / \mathrm{mL}$. One new purinyl-steroid (ergosta-4,6,8(14),22-tetraen-3-(6-amino-9H-purin-9-yl) (1)), along with six (2-7) known compounds, were isolated from the EtOAc extract of Penicillium brefeldianum ABC190807. Structures of the compounds were elucidated via 1D/2D NMR and HR-ESI-MS data. Respective spectral data were compared with those of known compounds. Among all compounds whose larvicidal activity against the third instar larvae of Aedes aegypti was evaluated, compounds 2 and 7 showed larvicidal activity with respective $\mathrm{LC}_{50}$ values of 0.452 and $0.337 \mathrm{mg} / \mathrm{mL}$.
\end{abstract}

\section{Introduction}

Marine natural products play a significant role in the drug discovery and development process, and marine-derived fungi are recognized as an emerging source for the production of novel and bioactive secondary metabolites [1-4]. At least 2000 novel natural products have been identified in the past five years, and nearly $50 \%$ of which were derived from marine-derived fungi [5]. Thus, there was great hope for developing new drugs from marine microorganisms, especially marine-derived fungi [6].

Penicillium is one of the most attractive fungal genera in the search for bioactive molecules [7]. More than 400 new marine natural products, including half the number of polyketides and a quarter the number of nitrogen compounds, have been isolated from marine-derived Penicillium fungi, and $58 \%$ of these new products display bioactivities such as anticancer, antibacterial, anti-HIV, and anti-inflammatory properties [8]. P. brefeldianum is a well-known Penicillium member, and its most famous product is the 16-membered macrolide antibiotic brefeldin A (6), an intracellular protein transport inhibitor, which can induce the differentiation and apoptosis of a wide variety of human cancer cells $[9,10]$.

In our process of studying natural pesticides from marine-derived fungi, we have focused on Penicillium brefeldianum ABC190807, which was isolated from mangrove sediments collected from Dongzhaigang Mangrove Nature Reserve, Hainan province, China, in August 2017. The EtOAc extract from a culture broth of this fungus exerted significant larvicidal activity against the third instar larvae of Aedes aegypti, as evidenced during preliminary screening. Mosquitoes historically posed a threat to human health, causing major global health issues that include malaria, dengue fever, yellow fever, and Zika, as well as several other vector-borne outbreaks [11]. Here, we set to search for significant bioactive natural products from Penicillium brefeldianum ABC190807. One new purinyl- 
steroid derivative (1) was isolated along with six (2-7) known compounds, from the extracts of Penicillium brefeldianum ABC190807, and their structures were elucidated (Figure 1). Herein, details of the isolation, structural elucidation, and larvicidal activities are presented.

\section{Materials and Methods}

2.1. General Experimental Procedures. Optical rotation was obtained with an MCP 200 digital polarimeter (Anton Paar, Austria). IR spectra were measured on TENSOR27 Fourier transform infrared spectrometer (Bruker Optics, Germany). UV spectra were recorded with a UV-2600 spectrometer (Shimadzu). 1D and 2D NMR spectra were measured on either a Bruker DRX $400 \mathrm{MHz}$ or $600 \mathrm{MHz}$ NMR spectrometer (Bruker Biospin Corporation, Fallanden, Switzerland) with tetramethylsilane (TMS) as the internal standard. HR-ESI-MS data were recorded on a liquid chromatography-mass spectrometry/ion trap/ time-of-flight (LCMS-IT-TOF) mass spectrometer (Shimadzu Corporation, Japan). Column chromatography (CC) was carried out on silica gel (60-80 and 200-300 mesh, Qingdao Marine Chemical Factory, Qingdao, China) and Sephadex LH-20 columns $(180 \mathrm{~cm} \times 2 \mathrm{~cm})$ (Pharmacia Fine Chemicals, Uppsala, Sweden). Fractions were monitored by thin-layer chromatography (TLC) using GF254 plates (Qingdao Marine Chemical Factory, Qingdao, China). Spots were detected under UV light or on heated TLC plates after soaking in $6 \% \mathrm{H}_{2} \mathrm{SO}_{4}$ in EtOH.

\subsection{Collection and Identification of Strain ABC190807.} The fungal strain ABC190807 was isolated from mangrove sediments collected from Dongzhaigang Mangrove Nature Reserve, Hainan province, China, in August 2017. The appropriate amount of the collected sample was placed in a $100-\mathrm{mL}$ triangle bottle containing $50 \mathrm{~mL}$ sterile seawater and then shaken at $28^{\circ} \mathrm{C}$ for $5 \mathrm{~min}$, before static settlement for $10 \mathrm{~min}$. A concentration gradient of $10^{-1}$ was obtained by drawing $1 \mathrm{~mL}$ sample solution from the triangle bottle into a test tube containing $9 \mathrm{~mL}$ sterile water, and the concentration gradients of $10^{-2}$ and $10^{-3}$ were obtained by further gradient dilution. Furthermore, $200 \mu \mathrm{L}$ of each concentration was coated on potato dextrose agar (PDA) plates (200 g potato, $20 \mathrm{~g}$ glucose, $20 \mathrm{~g}$ agar, and replenish with seawater to $1000 \mathrm{~mL}$; $\mathrm{pH}$ : 7.2-7.4), five times. Then, plates were sealed and cultured upside down. The strain was obtained by repeated inoculation of monoclonal colonies onto fresh PDA plates. The strain ABC190807 was identified as Penicillium brefeldianum based on its morphological characteristics and $18 \mathrm{~S}$ rDNA sequence analysis by comparison with other sequences in the GenBank database. The phylogenetic tree of the strain ABC190807 was built by multiple sequence alignment and Neighbor-Joining of MEGA X software (see Supplementary Table S1 and Figures M1-M3). The GenBank accession number of the sequence of this strain is MN264643.
2.3. Fermentation and Extraction. For large-scale fermentation, the fresh mycelia of Penicillium brefeldianum were cultured on the potato dextrose (PD) medium for two days in a shaker at $26 \pm 22^{\circ} \mathrm{C}$. The obtained liquid culture medium was inoculated into 150 fermentation flasks $(1000 \mathrm{~mL}$ triangular flasks, each containing $100 \mathrm{~mL}$ of PD medium) under aseptic conditions. The cultures were inoculated at $26 \pm 2^{\circ} \mathrm{C}$ for 40 days. After 40 days of cultivation, the fermented cultures were extracted three times with ethyl acetate (EtOAc), and the extracts were concentrated to yield $34.8 \mathrm{~g}$ of residue under reduced pressure.

2.4. Isolation and Purification. The obtained EtOAc crude extract $(34.8 \mathrm{~g})$ was subjected to a silica gel column $(60 \times 5 \mathrm{~cm})$ and eluted with a gradient of petroleum ether/ EtOAc (100:0-0:100, v/v) and divided into 16 fractions (Fr1-Fr-16). Fr-6 (2.1 g) was chromatographed on silica gel by CC (petroleum ether/EtOAc, $91: 9, \mathrm{v} / \mathrm{v}$ ) to give subfraction Fr-6-2. Fr-6-2 was subjected to Sephadex LH-20 CC $\left(\mathrm{CHCl}_{3} /\right.$ $\mathrm{MeOH}, 1: 1, \mathrm{v} / \mathrm{v})$ to give subfraction Fr-6-2-2, and silica gel $\mathrm{CC}$ (petroleum ether/EtOAc, $95: 5, \mathrm{v} / \mathrm{v}$ ) yielded compound 3 (52.5 mg). Fr-7 (3.8 g) was separated by silica gel CC (petroleum ether/EtOAc, $82: 18$, v/v) to give subfraction Fr-7-4, and Fr-7-4 was subjected to Sephadex LH-20 CC $\left(\mathrm{CHCl}_{3} /\right.$ $\mathrm{MeOH}, 1: 1, \mathrm{v} / \mathrm{v})$ to yield compound 2 (87.9 mg). Fr-9 (1.8 g) was separated by silica gel CC (petroleum ether/EtOAc, 77 : 23, v/v) to give subfraction Fr-9-2, and Fr-9-2 was subjected to Sephadex LH-20 CC $(\mathrm{MeOH})$ to yield compounds 7 (18.3 mg) and 4 (36.7 mg). Fr-10 (5.8 g) was separated by silica gel CC (petroleum ether/EtOAc, $72: 28$, v/v) to give subfraction Fr-10-5, and Fr-10-5 was subjected to Sephadex LH-20 CC (MeOH) to yield compound 5 (221.4 mg). Fr-13 $(2.3 \mathrm{~g})$ was separated by silica gel CC (petroleum ether/ EtOAc, $56: 44$, v/v) to give subfraction Fr-13-4, and Fr-13-4 was subjected to Sephadex $\mathrm{LH}-20 \mathrm{CC}\left(\mathrm{CHCl}_{3} / \mathrm{MeOH}, 1: 1\right.$, v/v) to give subfraction Fr-13-4-3, which was recrystallized to yield compound 1 (32.3 mg). Fr-14 (12.6 g) was separated by silica gel CC (petroleum ether/EtOAc, $50: 50$, v/v) to give subfraction Fr-14-4, and Fr-14-4 was purified by Sephadex $\mathrm{LH}-20 \mathrm{CC}(\mathrm{MeOH})$ to yield compound 6 (416.6 mg).

2.4.1. (3a 22E)-Ergosta-4, 6, 8(14),22-tetraen-3-(6-amino9H-purin-9-yl) (1). It is a pale yellow powder. $[\alpha]_{D}^{25}=+81.7$ $\left(c=0.0006, \mathrm{CHCl}_{3}\right)$. IR $\left(\mathrm{KBr}, v_{\max }\right): 3421,2957,2927,2854$, $1711,1651,1599,1457,1374,1332,1256,1122,1071,1014$, $971 \mathrm{~cm}^{-1}$. UV $\left(\mathrm{MeOH}, \lambda_{\max }\right): 230,260 \mathrm{~nm}$. For ${ }^{1} \mathrm{H}-\mathrm{NMR}$ $(400 \mathrm{MHz})$ and ${ }^{13} \mathrm{C}-\mathrm{NMR}(101 \mathrm{MHz})$ data, see Table 1 . HRESI-MS: $m / z \quad 512.3748 \quad[\mathrm{M}+\mathrm{H}]^{+}$(calcd. for $\mathrm{C}_{33} \mathrm{H}_{46} \mathrm{~N}_{5}$ 512.3753). Original spectra can be seen in Figures S1-S11.

2.5. Larvicidal Activity Assay. The larvicidal activities of compounds 1-7 were tested against the third instar larvae of A. aegypti using the bioassay system described by Pridgeon et al. [12]. However, our process differed slightly because of the small quantities of isolated extracts. The tested compounds were dissolved in a quantity of dimethyl sulfoxide (DMSO) and distilled water to obtain mother liquor with a 

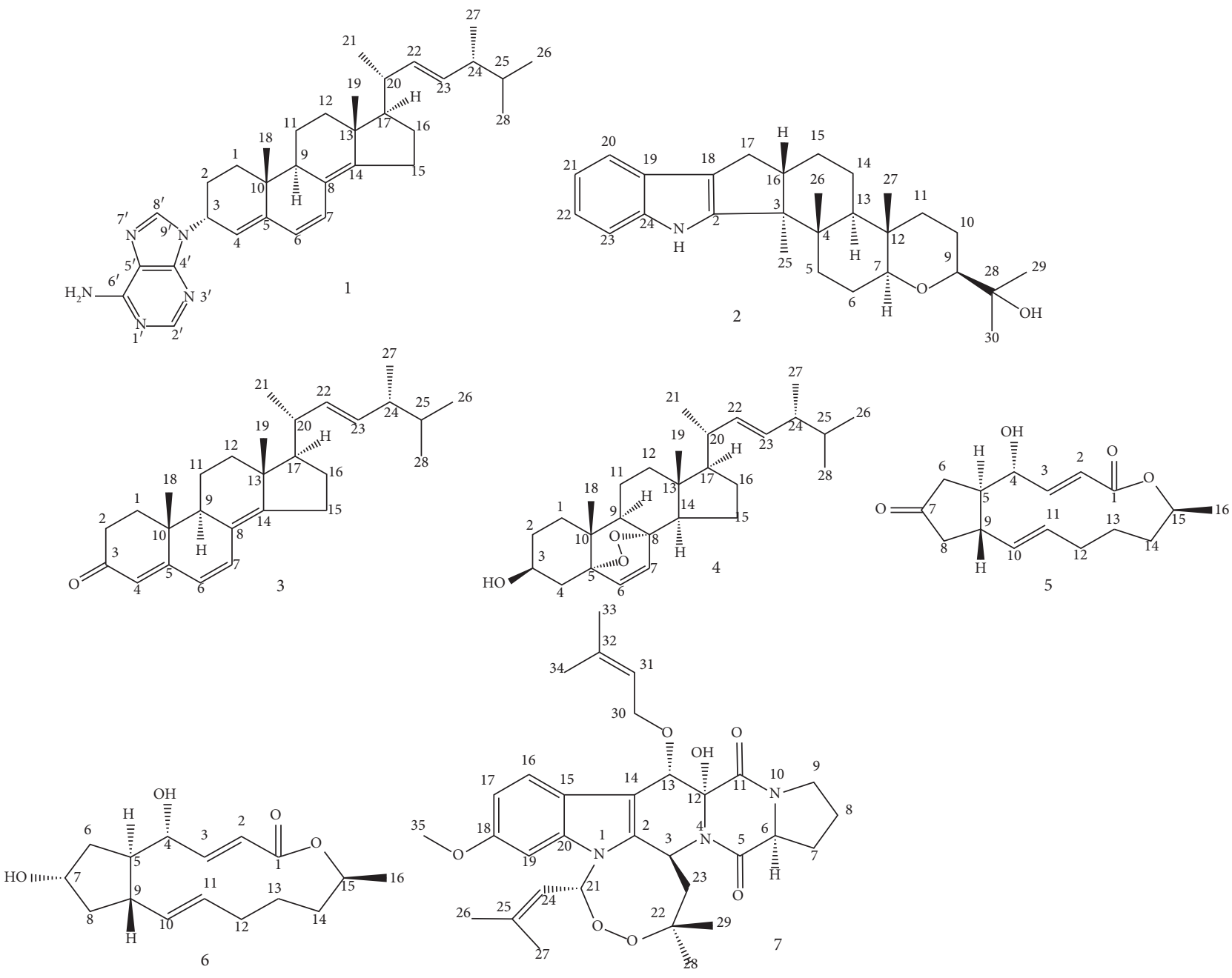

Figure 1: Chemical structures of compounds 1-7.

concentration of $1.000 \mathrm{mg} / \mathrm{mL}$. In some cases, a drop of Tween 20 was added to help disperse the compounds. Then, $1 \mathrm{~mL}$ of the mother liquor was added to a test tube containing $3 \mathrm{~mL}$ distilled water and 20 third instar larvae. The final concentration of the tested compounds was $0.250 \mathrm{mg}$ / $\mathrm{mL}$, and the DMSO concentration did not exceed 2\% (this concentration has been proven to have no significant effect on the larvae of Aedes aegypti). The natural insecticide rotenone (the crude drug was obtained from Pesticide Laboratory of Hainan University) and the same amount of DMSO or Tween 20 were used as positive and blank controls. Each experiment was carried out in triplicate. Larval mortality was recorded after $24 \mathrm{~h}$ of exposure. Larvae that showed no movement in the test tube after the manual agitation of the water was scored as dead. To calculate the $\mathrm{LC}_{50}$ values of the active compounds, the larval assays were repeated with five concentrations, yielding a range of 0-100\% mortality.

2.6. Statistical Analysis. All analyses were conducted in triplicate and are reported as means with standard deviations. For each set of results, the analysis of variance
(ANOVA) was applied, followed by the Dunnett or Tukey's test. $P<0.05$ was considered statistically significant.

\section{Results and Discussion}

3.1. Structure Elucidation. Compound 1 was obtained as a white amorphous powder, and its molecular formula was determined to be $\mathrm{C}_{33} \mathrm{H}_{45} \mathrm{~N}_{5}$ by positive high-resolution electrospray mass spectrometry (HR-ESI-MS, $\mathrm{m} / \mathrm{z}$ 512.3748 $[\mathrm{M}+\mathrm{H}]^{+}$, calcd. 512.3753) having 14 indices of hydrogen deficiency. The IR spectrum of 1 displayed absorption bands at $-\mathrm{NH}\left(3421 \mathrm{~cm}^{-1}\right)$, cyclic alkene (1711, $\left.1651,1599 \mathrm{~cm}^{-1}\right),-\mathrm{CH},-\mathrm{CH}_{2}$, and $-\mathrm{CH}_{3}(2957,2927,2854$, $\left.1457,1374 \mathrm{~cm}^{-1}\right)$. The UV spectrum of 1 showed maxima at 260 and $230 \mathrm{~nm}$, which suggested the presence of a conjugated system. The ${ }^{1} \mathrm{H}$-NMR spectrum (Table 1 ) of 1 in deuterated chloroform showed two purine hydrogen signals at $\delta_{\mathrm{H}} 8.38\left(\mathrm{br} \mathrm{s}, \mathrm{H}-\mathrm{C}\left(2^{\prime}\right), 1 \mathrm{H}\right)$ and 7.79 (br s, $\left.\mathrm{H}-\mathrm{C}\left(8^{\prime}\right), 1 \mathrm{H}\right)$, two mutual coupling olefinic protons at $\delta_{\mathrm{H}}$ 6.35 (br d, $J=9.7 \mathrm{~Hz}, \mathrm{H}-\mathrm{C}(7), 1 \mathrm{H}$ ) and 6.00 (br d, $J=9.7 \mathrm{~Hz}, \mathrm{H}-\mathrm{C}(6), 1 \mathrm{H})$, an amino active hydrogen signal at $\delta_{\mathrm{H}} 5.83(\mathrm{br} \mathrm{s}, 2 \mathrm{H})$, a coupling olefinic proton at $\delta_{\mathrm{H}} 5.56$ (br d, $J=4.8 \mathrm{~Hz}, \mathrm{H}-\mathrm{C}(4), 1 \mathrm{H}$ ), a coupling methine proton 
TAble 1: ${ }^{1} \mathrm{H}-\mathrm{NMR}(400 \mathrm{MHz})$ and ${ }^{13} \mathrm{C}-\mathrm{NMR}(101 \mathrm{MHz})$ data of compound 1 in $\mathrm{CDCl}_{3}$ ( $\delta$ in ppm, $J$ in $\mathrm{Hz}$ ).

\begin{tabular}{|c|c|c|c|}
\hline Position & $\delta_{(\mathrm{H})}$ & $\delta_{(\mathrm{C})}$ & HMBC \\
\hline $1 \alpha$ & $1.32(\mathrm{td}, 14.4,3.2)$ & $29.4 \mathrm{CH}_{2}$ & \\
\hline $1 \beta$ & $1.67-1.60(\mathrm{~m})$ & & \\
\hline $2 \alpha$ & $2.15-1.99(\mathrm{~m})$ & $25.5 \mathrm{CH}_{2}$ & \\
\hline $2 \beta$ & $2.24(\mathrm{tdd}, 14.4,5.2,3.3)$ & & \\
\hline 3 & $5.32(\mathrm{dd}, 4.8,5.2)$ & $48.9 \mathrm{CH}$ & $\mathrm{C}-8^{\prime}, 1,5^{\prime}, 1,5$ \\
\hline 4 & $5.56(\mathrm{~d}, 4.8)$ & $116.6 \mathrm{CH}$ & C- $2,10,6$ \\
\hline 5 & & $150.2 \mathrm{C}$ & \\
\hline 6 & $6.00(\mathrm{~d}, 9.7)$ & $124.7 \mathrm{CH}$ & \\
\hline 7 & $6.35(\mathrm{~d}, 9.7)$ & $128.1 \mathrm{CH}$ & \\
\hline 8 & & $124.2 \mathrm{C}$ & \\
\hline 9 & $2.13-2.05(\mathrm{~m})$ & $45.3 \mathrm{CH}$ & \\
\hline 10 & & $36.2 \mathrm{C}$ & \\
\hline 11 & $1.66-1.53(\mathrm{~m})$ & $19.5 \mathrm{CH}_{2}$ & \\
\hline $12 \alpha$ & $1.39-1.17(\mathrm{~m})$ & $35.9 \mathrm{CH}_{2}$ & \\
\hline $12 \beta$ & $2.15-1.99(\mathrm{~m})$ & & \\
\hline 13 & & $43.8 \mathrm{C}$ & \\
\hline 14 & & $151.7 \mathrm{C}$ & \\
\hline 15 & $2.57-2.31(\mathrm{~m})$ & $25.1 \mathrm{CH}_{2}$ & \\
\hline $16 \alpha$ & $1.50-1.43(\mathrm{~m})$ & $27.8 \mathrm{CH}_{2}$ & \\
\hline $16 \beta$ & $1.86-1.74(\mathrm{~m})$ & & \\
\hline 17 & $1.39-1.17(\mathrm{~m})$ & $55.9 \mathrm{CH}$ & \\
\hline 18 & $0.94(\mathrm{~s})$ & $17.6 \mathrm{CH}_{3}$ & $\mathrm{C}-1,5,9$ \\
\hline 19 & $0.95(\mathrm{~s})$ & $19.1 \mathrm{CH}_{3}$ & C- $12,14,17$ \\
\hline 20 & $2.23-2.10(\mathrm{~m})$ & $39.3 \mathrm{CH}$ & \\
\hline 21 & $1.05(\mathrm{~d}, 6.7)$ & $21.2 \mathrm{CH}_{3}$ & C- 17,22 \\
\hline 22 & $5.20(\mathrm{dd}, 15.3,7.7)$ & $135.2 \mathrm{CH}$ & \\
\hline 23 & $5.25(\mathrm{dd}, 15.3,7.1)$ & $132.3 \mathrm{CH}$ & \\
\hline 24 & $1.94-1.83(\mathrm{~m})$ & $42.9 \mathrm{CH}$ & \\
\hline 25 & $1.52-1.43(\mathrm{~m})$ & $33.1 \mathrm{CH}$ & \\
\hline 26 & $0.83(\mathrm{~d}, 6.7)$ & $19.6 \mathrm{CH}_{3}$ & C-24 \\
\hline 27 & $0.93(\mathrm{~d}, 6.7)$ & $17.6 \mathrm{CH}_{3}$ & C-23, 25 \\
\hline 28 & $0.85(\mathrm{~d}, 6.7)$ & $20.0 \mathrm{CH}_{3}$ & C-24 \\
\hline $2^{\prime \prime}$ & $8.38(\mathrm{~s})$ & $152.6 \mathrm{CH}$ & $C-6^{\prime}, 4^{\prime}, 4^{\prime}$ \\
\hline $4^{\prime}$ & & $149.4 \mathrm{C}$ & \\
\hline $5^{\prime}$ & & $120.2 \mathrm{C}$ & \\
\hline $6^{\prime}$ & & $155.3 \mathrm{C}$ & \\
\hline $8^{\prime}$ & $7.79(\mathrm{~s})$ & $140.2 \mathrm{CH}$ & C- $4^{\prime}, 5^{\prime}, 5^{\prime}$ \\
\hline $\begin{array}{l}6^{\prime}-\mathrm{NH}_{2-} \\
\mathrm{NH}_{2}\end{array}$ & $5.83(\mathrm{~s})$ & & \\
\hline
\end{tabular}

at $\delta_{\mathrm{H}} 5.32(\mathrm{br} \mathrm{dd}, J=5.2,4.8 \mathrm{~Hz}, \mathrm{H}-\mathrm{C}(3), 1 \mathrm{H})$, and a pair of trans-coupling olefinic protons at $\delta_{\mathrm{H}} 5.25(\mathrm{dd}, J=15.3$, $7.1 \mathrm{~Hz}, \mathrm{H}-\mathrm{C}(23), 1 \mathrm{H})$ and $5.20(\mathrm{dd}, J=15.3,7.7 \mathrm{~Hz}$, $\mathrm{H}-\mathrm{C}(22), 1 \mathrm{H})$, which are characteristic of the side-chain of a steroid molecule, as well as four methyl doublets at $\delta_{\mathrm{H}}$ $1.05,0.93,0.85$, and 0.83 and two methyl singlets at $\delta_{\mathrm{H}} 0.95$ and 0.94 . The ${ }^{13} \mathrm{C}$ NMR spectrum (Table 1) showed a total of 33 carbon resonances, including $13 \mathrm{sp}^{2}$ carbon and 20 $\mathrm{sp}^{3}$ carbon signals. The above NMR spectroscopic data are characteristic signals of ergosta-4, 6, 8(14), 22-tetraen-3one [13] and adenine [14], which suggests that 1 is a hybrid of the two molecules. Considering that the $\mathrm{C}(3)$ ketocarbonyl carbon signal of the steroid nucleus is replaced by a new methine signal $\left(\delta_{\mathrm{H}} 5.32(\mathrm{br} \mathrm{dd}, J=5.2,4.8 \mathrm{~Hz}) ; \delta_{\mathrm{C}}\right.$ $48.9)$, we inferred that the hybrid molecule was connected between $C(3)$ of the steroid nucleus and $N\left(9^{\prime}\right)$ of the adenine moiety $[15,16]$, and this deduction was further confirmed by heteronuclear multiple bond correlation

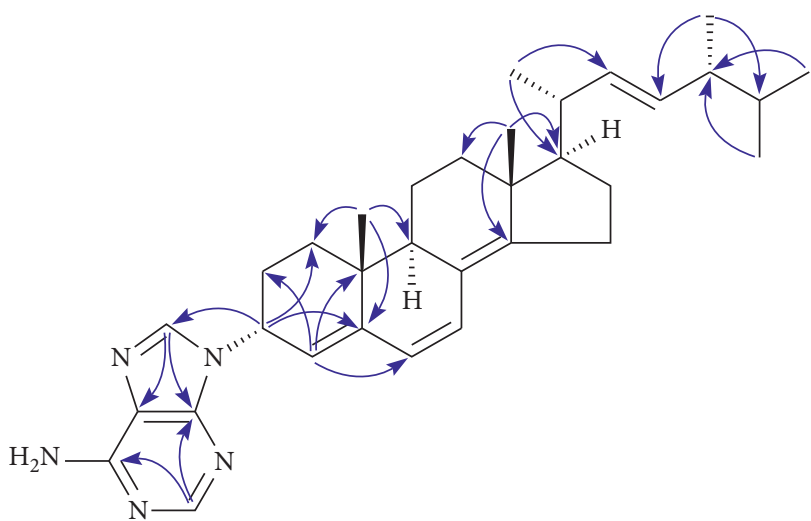

Figure 2: HMBC (H-C) data of compound 1.

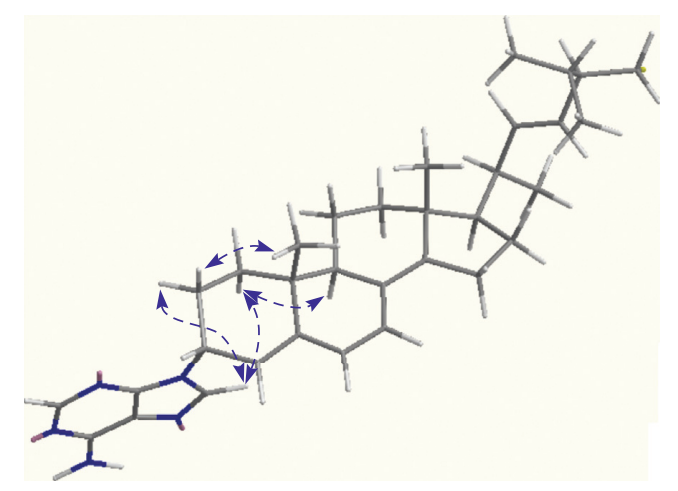

Figure 3: NOESY correlations of compound 1.

(HMBC) experiments (Figure 2) from $\mathrm{H}(3)\left(\delta_{\mathrm{H}} 5.32(\mathrm{br}\right.$ dd, $J=5.2,4.8 \mathrm{~Hz}), 1 \mathrm{H})$ to $\mathrm{C}(1)\left(\delta_{\mathrm{C}} 29.4 \mathrm{ppm}(\mathrm{t})\right), \mathrm{C}(5)\left(\delta_{\mathrm{C}}\right.$ $150.2 \mathrm{ppm}(\mathrm{s}))$, and $\mathrm{C}\left(8^{\prime}\right) \quad\left(\delta_{\mathrm{C}} 140.2 \mathrm{ppm}(\mathrm{d})\right)$. The chemical shift of $\mathrm{C}(3)\left(\delta_{\mathrm{C}} 48.9 \mathrm{ppm}(\mathrm{d})\right)$ revealed that the adenine moiety is $\alpha$-oriented (axial direction) [15]. The stereochemistry of $\mathrm{C}(3)$ was further confirmed from the following nuclear Overhauser effect spectroscopy (NOESY) correlations (Figure 3): $\mathrm{H}\left(8^{\prime}\right) \longleftrightarrow \mathrm{H}(1 \alpha) / \mathrm{H}(2 \alpha), \mathrm{H}(1 \alpha) \longleftrightarrow$ $\mathrm{H}(9)$, and $\mathrm{H}(2 \beta) \longleftrightarrow \mathrm{Me}-18$. Therefore, the structure of 1 was established, as shown in Figure 1, and named ergosta4,6,8(14),22-tetraen-3-(6-amino-9H-purin-9-yl) ( $3 \alpha 22 E)$. It is worth pointing out that this new steroid is the first naturally occurring hybrid molecule composed of ergosterol and a nucleoside.

In addition, the structures of paspaline (2) [17], (22E)ergosta-4,6,8(14),22-tetraen-3-one (3) [13], ergosterol peroxide (4) [18], 7-dehydrobrefeldin A (5) [19], brefeldin A (6) [20], and fumitremorgin A (7) [21] were determined by comparing the NMR data with those reported in the literature.

3.2. Larvicidal Activity. The EtOAc extract of the mangrove sediment fungi Penicillium brefeldianum ABC190807 exerted larvicidal activity against Aedes aegypti with $\mathrm{LC}_{50}$ values of $0.089 \mathrm{mg} / \mathrm{mL}$ (see Supplementary Table S2). At $0.250 \mathrm{mg} / \mathrm{mL}$, compounds 2 and 7 exhibited lethal activity against the larvae, whereas the other compounds were 
TABLE 2: Larvicidal activities of paspaline (2) and fumitremorgin A (7).

\begin{tabular}{lccr}
\hline Compounds & & $\mathrm{LC}_{50}(95 \%$ confidence interval $(\mathrm{CI}))(\mathrm{mg} / \mathrm{mL})$ & $48 \mathrm{~h}$ \\
\hline Paspaline & $24 \mathrm{~h}$ & $36 \mathrm{~h}$ & $0.452(0.320-0.521)$ \\
Fumitremorgin A & $\mathrm{PD}^{\mathrm{a}}$ & $0.743(0.672-0.887)$ & $0.337(0.232-0.398)$ \\
Rotenone $^{\mathrm{b}}$ & $0.570(0.523-0.617)$ & $0.408(0.335-0.456)$ & $0.044(0.041-0.047)$ \\
\hline
\end{tabular}

${ }^{a}$ PD: poor data performance. ${ }^{b}$ Positive control.

inactive at the tested concentration (see Supplementary Table S3). The larvicidal activities (median lethal concentration, $\mathrm{LC}_{50}$ ) of 2,7 , and the positive control were assessed after 24,36 , and $48 \mathrm{~h}$ of exposure, and the results are shown in Table 2. The results showed that the lethality of the positive control rotenone $(0.044 \mathrm{mg} / \mathrm{mL})$ was about 10 times that of $2(0.452 \mathrm{mg} / \mathrm{mL})$ and 8 times that of $7(0.337 \mathrm{mg} / \mathrm{mL})$ after $48 \mathrm{~h}$ of exposure.

Paspaline (2) has also been reported to have other biological effects; for example, its cytotoxicities $\left(\mathrm{IC}_{50}\right)$ against three human cancer cell lines, MDA-MB-231, US-OS, and HepG2 were $14.5,12.0$, and $32.1 \mu \mathrm{mol} / \mathrm{L}$, respectively [22]. It also exhibited good activity against the human pathogen Escherichia coli, having minimum inhibitory concentration (MIC) values of $0.5 \mu \mathrm{g} / \mathrm{mL}$ [23]. However, to our knowledge, this is the first study to report paspaline's larvicidal activity (2).

Fumitremorgin A (7) and some of its analogs have been reported to have potent lethality against brine shrimp (Artemia Salina) [24] and have strong inhibitory activity against the BRD4 protein [25], which is a member of the BET protein family, and an important therapeutic target for major diseases such as cancer, neurological disorders, obesity, and inflammation; thus, effective BET inhibitors are being sought [26], However, to our knowledge, this is the first study to report the larvicidal activity of fumitremorgin A (7).

\section{Conclusions}

A new purinyl-steroid (1), along with six (2-7) known compounds, was isolated from the extracts of the mangrove sediment fungi Penicillium brefeldianum ABC190807. The compounds' structures were elucidated via $1 \mathrm{D} / 2 \mathrm{D}$ NMR and high-resolution electrospray mass spectrometry and by comparing the respective spectral data with reported compounds. Compounds 2 and 7 showed larvicidal activity against the third instar larvae of Aedes aegypti. The compounds isolated from Penicillium brefeldianum ABC190807 have a wide range of biological activities, indicating that this strain has good research value. The new method of screening secondary microbial metabolites can further explore the synthetic potential of the secondary metabolites of this strain to find other active compounds with a novel structure.

\section{Data Availability}

The data used to support the finding of this study are available from the corresponding author upon request.

\section{Conflicts of Interest}

The authors declare that there are no conflicts of interest.

\section{Acknowledgments}

This research was financially supported by the Monitoring and Control of a Major Invasive Species in Hainan Province: Lepidoptera litura and Solenopsis invicta, Ministry of Agriculture and Rural Affairs (no. 1630042020020), Hainan Province key R \& D Program (no. ZDYF2016184), National Natural Science Foundation of China (no. 31360447), and Key Laboratory of Green Prevention and Control of Tropical Plant Diseases and Pests, Hainan University, Ministry of Education.

\section{Supplementary Materials}

Identification data of strain $\mathrm{ABC} 190807$ and spectral data of compounds 1-7 (Figures S1-S29). (Supplementary Materials)

\section{References}

[1] M. E. Rateb and R. Ebel, "Secondary metabolites of fungi from marine habitats," Natural Product Reports, vol. 28, no. 2, pp. 290-344, 2011.

[2] W. H. Gerwick and B. S. Moore, "Erratum: Lessons from the past and charting the future of marine natural products drug discovery and chemical biology," Chemistry \& Biology, vol. 19, no. 12, p. 1631, 2012.

[3] J. W. Blunt, B. R. Copp, R. A. Keyzers, M. H. G. Munro, and M. R. Prinsep, "Marine natural products," Natural Product Reports, vol. 34, no. 3, pp. 235-294, 2017.

[4] E. Ancheeva, G. Daletos, and P. Proksch, "Lead compounds from mangrove-associated microorganisms," Marine Drugs, vol. 16, no. 9, p. 319, 2018.

[5] J. W. Blunt, A. R. Carroll, B. R. Copp, R. A. Davis, R. A. Keyzers, and M. R. Prinsep, "Marine natural products," Natural Product Reports, vol. 35, no. 1, pp. 8-53, 2018.

[6] J. W. Blunt, B. R. Copp, R. A. Keyzers, M. H. G. Munro, and M. R. Prinsep, "Marine natural products," Natural Product Reports, vol. 33, no. 3, pp. 382-431, 2016.

[7] S. Liu, M. Su, S.-J. Song, and J. Jung, "Marine-derived Penicillium species as producers of cytotoxic metabolites," Marine Drugs, vol. 15, no. 10, p. 329, 2017.

[8] H.-G. Ma, Q. Liu, G.-L. Zhu, H.-S. Liu, and W.-M. Zhu, "Marine natural products sourced from marine-derived Penicillium fungi," Journal of Asian Natural Products Research, vol. 18, no. 1, pp. 92-115, 2016.

[9] J.-W. Zhu, H. Nagasawa, F. Nagura et al., "Elucidation of strict structural requirements of brefeldin A as an inducer of differentiation and apoptosis," Bioorganic \& Medicinal Chemistry, vol. 8, no. 2, pp. 455-463, 2000. 
[10] J.-W. Zhu, H. Hori, H. Nojiri, T. Tsukuda, and Z. Taira, "Synthesis and activity of brefeldin A analogs as inducers of cancer cell differentiation and apoptosis," Bioorganic \& $\mathrm{Me}$ dicinal Chemistry Letters, vol. 7, no. 2, pp. 139-144, 1997.

[11] D. R. Ravindran, M. Bharathithasan, P. Ramaiah et al., "Chemical composition and larvicidal activity of flower extracts from Clitoria ternatea against Aedes (Diptera: Culicidae)," Journal of Chemistry, vol. 2020, Article ID 3837207, 17 pages, 2020.

[12] J. W. Pridgeon, J. J. Becnel, G. G. Clark, and K. J. Linthicum, "A high-throughput screening method to identify potential pesticides for mosquito control," Journal of Medical Entomology, vol. 46, no. 2, pp. 335-341, 2009.

[13] Y. S. Tsantrizos, P. L. Folkins, J. F. Britten, D. N. Harpp, and K. K. Ogilvie, "Approaches towards the synthesis of a sulfur analog of ergosterol peroxide," Canadian Journal of Chemistry, vol. 70, no. 1, pp. 158-164, 1992.

[14] R. Saladino, C. Crestini, V. Neri, F. Ciciriello, G. Costanzo, and E. Di Mauro, "Origin of informational polymers: the concurrent roles of formamide and phosphates," ChemBioChem, vol. 7, no. 11, pp. 1707-1714, 2006.

[15] R. A. Cadenas, M. E. Gelpi, and J. Mosettig, "Nucleosteroids: synthesis of purinyl-steroid derivatives under mitsunobu reaction conditions," Journal of Heterocyclic Chemistry, vol. 42, no. 1, pp. 1-3, 2005.

[16] M. E. Gepli, R. A. Cadenas, J. Mosettig, and B. N. Zuazo, "Nucleoteroids: carbocyclic nucleoside analogs of androst-4en-17 $\beta$-ol," Steroids, vol. 67, no. 3-4, pp. 263-267, 2002.

[17] R. E. Mewshaw, M. D. Taylor, and A. B. Smith, "Indole diterpene synthetic studies. 2. First-generation total synthesis of (-)-paspaline," The Journal of Organic Chemistry, vol. 54, no. 14 , pp. $3449-3462,1989$.

[18] Y. J. Kim, J. Park, B. S. Min, and S. H. Shim, "Chemical constituents from the sclerotia of Inonotus obliquus," Applied Biological Chemistry, vol. 54, no. 2, pp. 287-294, 2011.

[19] M. G. D. L. Parra and C. R. Hutchinson, "Macrolide biosynthesis: stereochemistry of the hydroxylation of brefelding C," The Journal of Antibiotics, vol. 40, no. 8, pp. 1170-1174, 1987.

[20] Y.-G. Suh, J.-K. Jung, S.-Y. Seo et al., "Total synthesis of (+)-brefeldin A," The Journal of Organic Chemistry, vol. 67, no. 12, pp. 4127-4137, 2002.

[21] H. Fujimoto, T. Akiyama, U. Sankawa et al., "Chemistry of tremorogenic metabolites. II. Structure determination of fumitremorgin B, a tremorogenic metabolite from Aspergillus fumigatus," Chemical \& Pharmaceutical Bulletin, vol. 28, no. 3, pp. 861-865, 1980.

[22] N. Gao, Z.-C. Shang, P. Yu et al., "Alkaloids from the endophytic fungus Penicillium brefeldianum and their cytotoxic activities," Chinese Chemical Letters, vol. 28, no. 6, pp. 1194-1199, 2017.

[23] X. Y. Hu, L. H. Meng, X. Li et al., "Three new indole diterpenoids from the sea-anemone-derived fungus Penicillium $s p$. AS-79," Marine Drugs, vol. 15, no. 5, p. 137, 2017.

[24] C.-Y. An, X.-M. Li, C.-S. Li, G.-M. Xu, and B.-G. Wang, "Prenylated indolediketopiperazine peroxides and related homologues from the marine sediment-derived fungus Penicillium brefeldianum SD-273," Marine Drugs, vol. 12, no. 2, pp. 746-756, 2014.

[25] L. Yu, W. Ding, Q. Wang et al., "Induction of cryptic bioactive 2,5-diketopiperazines in fungus Penicillium sp. DT-F29 by microbial co-culture," Tetrahedron, vol. 73, no. 7, pp. 907-914, 2017.
[26] B. Padmanabhan, S. Mathur, R. Manjula, and S. Tripathi, "Bromodomain and extra-terminal (BET) family proteins: new therapeutic targets in major diseases," Journal of Biosciences, vol. 41, no. 2, pp. 295-311, 2016. 